\title{
Association of Polymorphisms in RGS4 and Expression of RGS transcripts in the Brains of Human Alcoholics
}

by

Ada M.-C. Ho ${ }^{1}$, Rachel K MacKay ${ }^{1}$, Peter R. Dodd ${ }^{2}$ and Joanne M. Lewohl ${ }^{1}$

${ }^{1}$ School of Medical Sciences, Griffith University, Gold Coast Campus, Southport, Australia,

${ }^{2}$ School of Chemistry and Molecular Biosciences, University of Queensland, Brisbane, Australia

Number of text pages: 25

Number of Figures and Tables: 3 Figures, 4 Tables

Address correspondence to: Dr J. M. Lewohl, Genomics Research Centre, Griffith Institute for Health and Medical Research, Gold Coast Campus, Griffith University, PMB 50 Gold Coast Mail Centre, Qld 9726, AUSTRALIA. TEL +61-7-5552-7096; FAX +61-7-5552-8908; email

j.lewohl@griffith.edu.au 


\begin{abstract}
Chronic alcoholism leads to neurotoxic effects in the central nervous system. Neuroadaptive changes in the brain may lead to tolerance to, and dependence on, alcohol as a result of alterations in synaptic complexity. G-proteins are negatively regulated by RGS proteins, which are integral to many neural pathways that include neurotransmission, hormonal responses, and chemotactic signals. These considerations, together with findings from microarray analyses of human autopsy brain, suggest that proteins involved in G-protein signalling, specifically the RGS protein family, may play an important role in the functioning of neural systems that are affected by chronic alcohol abuse. We used Real Time PCR to measure the expression of two members of the RGS family, RGS4 and RGS7, in the superior frontal gyrus and primary motor cortex from alcoholic and non-alcoholic cases. Overall, cirrhotic alcoholics had lower expression levels of RGS4 mRNA than controls and non-cirrhotic alcoholics. We also report that the four RGS4 SNPs (SNP1, 4, 7 and 18) may be associated with alcoholism in European Caucasians at the haplotype level. The haplotype T-C-G (SNP1-4-18) may exert a protective effect against alcoholism.
\end{abstract}

\title{
Classification terms:
}

Section: 1. Cellular and Molecular Biology of Nervous Systems

Keywords: Sex differences, G-protein signaling, cirrhosis, Real Time PCR

Abbreviations used: RGS, regulator of G-protein signaling; WKS, Wernicke-Korsakoff Syndrome; G-protein, guanine nucleotide binding protein; MOR, mu-opioid receptor; PMI, post-mortem interval; GAPDH, Glyceraldehyde-3-phosphate dehydrogenase; HPRT, hypoxanthine phosphoribosyl transferase; ENO2, enolase 2 (neuron-specific enolase); SYP, synaptophysin; $\mathrm{C}_{\mathrm{T}}$, cycle threshold; SNP, single nucleotide polymorphism; HWE, Hardy-Weinberg equilibrium; LD, linkage disequilibrium; HRM, High resolution melting; SNP, single nucleotide polymorphism. 


\section{Introduction}

Chronic and excessive alcohol consumption has deleterious effects on the CNS, where it has been shown to cause brain damage to specific areas of the cerebral cortex (Kril et al. 1997).

Neuropathological studies have shown that alcoholics have reduced brain weights and brain atrophy compared with non-drinking controls, and that the extent of atrophy can be correlated with estimates of lifetime alcohol consumption (Harding et al. 1996; Harper 1998; Kril and Halliday 1999). The reduced brain weight in alcoholics is attributed to a loss of white matter (Harper et al. 1985; de la Monte 1988) but cortical grey matter is also affected. Alcoholics show reduced dendritic arborization in a number of cortical regions, although neuronal loss only occurs in discrete regions, particularly the superior frontal gyrus (Kril and Harper 1989).

CNS damage is more severe in alcoholics who have concomitant diseases such as cirrhosis of the liver or the Wernicke-Korsakoff Syndrome (WKS) (Kril and Harper 1989). Women may be more vulnerable to the development of alcoholic brain damage (Mann et al. 1992). Neuropathological and neuroimaging studies suggest that the brain damage in alcoholic women is similar to that in men despite a shorter drinking history and lower peak alcohol consumption (Jacobson 1986; Harper et al. 1990; Harper 1998; Pfefferbaum et al. 2001). Female alcoholics are also more susceptible to greymatter injury and cognitive deterioration than males (Schweinsburg et al. 2003; Wang et al. 2003).

In the brain, the acute effects of alcohol are mediated by interactions with various neurotransmitter and signalling systems. Long term alcoholism results in adaptive changes in neuronal function which may be mediated by changes in gene expression (Nestler and Aghajanian 1997). Microarray and proteomic studies have identified a number of genes involved in synaptic function and cell signalling which are differentially regulated in the frontal cortex of human alcoholics (Lewohl et al. 2000; Mayfield et al. 2002; Lewohl et al. 2004; Liu et al. 2004).

Regulator of G-protein signaling (RGS) proteins negatively modulate G-protein signalling thereby significantly influencing the kinetics and strength of in vivo receptor signalling pathways of the 
central nervous system and heart (Hooks et al. 2008). The RGS family is functionally and structurally diverse with 37 genes in the human genome containing RGS or RGS-like domains (Siderovski and Willard 2005; Willars 2006). Despite this diversity, RGS proteins share a conserved 125-amino-acid domain that forms the major contact sites with $\mathrm{G}_{\alpha}$ subunit. Such contact stabilizes the binding between $\mathrm{G}_{\alpha}$ and the transition state analogue of GTP hydrolysis, hence accelerating the $\mathrm{G}_{\alpha}$ subunit GTP-hydrolytic activity (Tesmer et al. 2005).

The potent role played by RGS proteins in drug addiction is demonstrated by their wide distribution of mRNA expression and protein throughout the brain, including parts of the limbic system and reward pathway such as amygdala, stria terminalis and ventral tegmental area (Hooks et al. 2008). Moreover, cell culture and animal studies showed that RGS proteins are associated with modulation of responses to substances of abuse, and their mRNA expression is reciprocally affected by these drugs. For example, RGS4 negatively modulates $\mu$-opioid receptor (MOR) signalling (Georgoussi et al. 2006) while acute morphine injection leads to increased transcription in nucleus accumbens (Bishop et al. 2002). The R7 RGS family (RGS6, RGS7, RGS9 and RGS11) also shows dramatic regulation by opioids; for example, RGS9 knockout mice demonstrated increased sensitivity to and more severe dependence on morphine (Zachariou et al. 2003). Although the function of RGS4 and its role in the pathophysiology of neuropsychiatric disorders such as schizophrenia and addiction remain unknown, RGS4 modulates serotonergic and dopaminergic signalling in the prefrontal cortex (Gu et al.) and may therefore play a role in mediating the effects of chronic alcohol abuse.

In microarray studies RGS4 is differentially expressed in the brain of human alcoholics (Lewohl et al. 2000). Although genetic associations between RGS4 and alcoholism have not been explored, RGS4 is a candidate gene for schizophrenia. RGS4 is located on chromosome 1q23.3. A wholegenome association study identified SNPs in 13 genes associated with both alcoholism and schizophrenia, two of which are located at 1q22-23 (Namkung et al. 2005). Four RGS4 SNPs and two haplotypes were found to be associated with schizophrenia by Chowdari et al. (2002) using a family-based approach: three localized in the upstream sequence [SNP1 (rs10917670); SNP4 
(rs951436); SNP7 (rs951439)] and one in the first intron [SNP18 (rs2661319)]. A recent fMRI study showed that RGS4 SNP4 A allele carriers had reduced gray and white matter volume in certain prefrontal areas (Buckholtz et al. 2007). Another recent promoter activity study suggests that a 5' upstream region, which includes SNP1, 4 and 7, may act as a repressor on RGS4 expression (Chowdari et al. 2008).

We studied the expression of RGS4 and RGS7 transcripts in human autopsy tissue from wellcharacterized alcoholics and matched controls. The data suggest that RGS4 but not RGS7 is differentially expressed in alcoholics and that there are sex differences in expression. As no previous study has explored the genetic association between polymorphisms in RGS4 and alcoholism, we also determined whether such association occurs in European Caucasians using a case-control approach.

\section{Results}

We analysed the expression levels of three commonly used housekeeping genes, GAPDH (glyceraldehyde-3-phosphate dehydrogenase), $\beta$-actin and HPRT (hypoxanthine phosphoribosyl transferase), as well as two brain-specific genes, neuron specific enolase (ENO2) and synaptophysin (SYP) to determine the most appropriate housekeeper for analysis. The expression of each of these transcripts was measured using Real Time PCR in every sample. Comprehensive statistical analysis was carried out on the raw $\mathrm{C}_{\mathrm{T}}$ values for each gene. No significant differences were found in the expression of GAPDH, $\beta$ actin or ENO2 between groups, genders or brain regions. No significant differences were found in the expression of HPRT between groups or areas, but there was a significant difference in the expression of this transcript between males and females $\left(F_{1,49}=6.2, P<\right.$ 0.02). There was a significant difference between ground for synaptophysin in the frontal cortex $\left(F_{1,63}=6.822, P=0.02\right)$ but not in the motor cortex $\left(F_{1,61}=2.12, P=1.3\right)$ making it unsuitable to be used as a house-keeping gene. BestKeeper, a software program designed to select the most appropriate house keeping gene for a given study, identified GAPDH as the ideal housekeeper for the data set. Accordingly, $\mathrm{C}_{\mathrm{T}}$ values for RGS4 and RGS7 were expressed relative to the $\mathrm{C}_{\mathrm{T}}$ value of GAPDH for each sample. 
To determine if the expression of RGS4, or RGS7 was correlated with age at death, post-mortem interval (PMI) or brain weight, linear regression was performed on each parameter. Regression analysis was carried out using all subjects combined and with subjects separated according to alcohol status (controls vs. combined alcoholics). There was no significant correlation between either RGS4 or RGS7 expression and age at death or post mortem interval (PMI) for combined cases or for cases separated into their respective groups.

The expression of RGS4 mRNA was significantly correlated with brain weight (frontal, $F_{1,59}=$ 8.597, $\mathrm{P}=0.005$; motor, $\left.F_{1,57}=12.956, P=0.001\right)$. When the groups were separated into controls and combined alcoholics, RGS4 (frontal, $F_{1,36}=9.036, P<0.005$; motor, $F_{1,36}=13.029, P=0.001$ ) showed significant regressions on brain weight in combined alcoholics but not in controls. To determine whether these regressions differed, a test of homogeneity of slopes was applied (Wilkinson. et al. 1992). The Group x Brain Weight interaction was not significant (RGS4 frontal: $F_{2,55}=0.9, P=0.4$; motor: $F_{2,54}=0.6, P=0.55$ ), which showed there was no difference between the slopes of the regression lines in the two groups. Since the case-groups did not differ significantly on brain weight (above), a simple factorial ANOVA was appropriate to analyse the data. The regression analyses described above were repeated in case-groups divided by gender. No difference was found between males and females in any of these tests.

In both frontal and motor cortices, RGS4 transcript levels differed significantly between groups (frontal, $F_{2,58}=7.135, P=0.0017$; motor, $F_{2,56}=5.678, P=0.0057$; Figure 1 ). Cirrhotic alcoholics had lower RGS4 expression than controls (frontal, $P<0.01$; motor, $P=0.01$ ) or non-cirrhotic alcoholics (frontal $P<0.02$; motor, $P<0.03$ ) on post-hoc tests. There was an overall difference between males and females, with RGS4 transcript levels being significantly lower in females than males $\left(F_{1,50}=6.75, P=0.012\right)$. Post-hoc testing showed that the expression of RGS4 was significantly lower in cirrhotic alcoholic males than control males (frontal, $P<0.002$; motor, $P<$ 0.02) or non-cirrhotic alcoholic males (frontal, $P<0.006$; motor, $P<0.05$ ) in both brain regions. There were no such differences in female cases and controls. 
There was no difference in expression of RGS7 either between case groups or between brain regions (frontal, $F_{2,58}=1.7, P=0.2$; motor, $F_{2,56}=1.6, P=0.2$; Figure 2).

Figures $1 \& 2$ about here

Genotyping results are shown in Table 1. For genotype distribution, no significant difference was observed between controls and alcoholics for SNP1, 4 and 7, only a marginal, non-significant difference was observed in SNP18 $\left(\chi^{2}=5.600 ; P=0.073\right)$. The genotype distributions of SNP 1,4 and 18 in both controls and alcoholics were in Hardy-Weinberg equilibrium (Schweinsburg et al.). For SNP7, genotype distribution of alcoholics was in HWE but was not for controls (exact $P=$ 0.017). For allele frequency, no significant difference was observed between the groups for any of the SNPs.

Table 1 about here

Linkage disequilibrium (LD) analysis showed that all four SNPs were in moderate to strong pairwise LD ( $\left.D^{\prime}: 0.74-0.93 ; r^{2}: 0.50-0.79\right)$. Compared with previous family-based genetic studies in schizophrenia (e.g. Zhang, et al. (2005), Chowdari, et al. (2008)), the LD of the four RGS4 SNPs are not as strong, because the case-control approach involves unrelated individuals.

In two-marker haplotype analysis (Table 2), the frequency of haplotype T-G (SNP1-18) was significantly lower in alcoholics (permutated $\chi^{2}=9.274$; permutated $P=0.0091$ ). In three-marker haplotype analysis (Table 2), haplotype T-C-G (SNP1-4-18) was detected with a significantly lower frequency in alcoholics than controls (permutated $\chi^{2}=8.339$; permutated $P=0.0126$ ). In fourmarker haplotype analysis, a significant difference in haplotype frequency of T-C-C-G (SNP1-4-718) was detected; however, since the genotypic distribution of SNP7 deviated significantly from 
HWE in controls, this result can only provide weak support for SNP7 involvement.

Table 2 about here

Partitioning of the expression data according to each individual's RGS4 genotype had no effect for any of the SNPs individually or in combination. Probable haplotypes for each individual were assigned using PHASE. Within the expression cohort, only two control individuals were predicted to have the protective RGS4 haplotype. Although these individuals had higher expression of RGS4 compared with those without the protective haplotype, this did not reach significance most likely due to the small number of cases with the protective haplotype in this population.

\section{Discussion}

The expression of RGS4 and RGS7 transcripts were measured in the superior frontal gyrus and primary motor cortex of control, non-cirrhotic alcoholic and cirrhotic alcoholic cases using Real Time RT-PCR. Overall, the expression of RGS4 was significantly lower in cirrhotic alcoholics than in controls or alcoholics without co-morbid disease. The effect of alcohol on the expression of this transcript was particularly marked in males; the RGS4 transcript was significantly less abundant in male cirrhotic alcoholics than in male controls. There was no such reduction of these transcripts in female cases. Further studies should be carried out to determine if RGS4 is regulated via different mechanisms in males and females. In contrast, there was no difference in RGS7 expression between controls and alcoholics overall, or between males and females.

The primers used to measure RGS4 expression amplified three of the five known splice variants (Ding et al.). These splice variants are differentially expressed in the human brain and have been shown to be differentially regulated in schizophrenia (Ding and Hegde 2009). Although no difference in expression was seen in alcoholics without co-morbid disease, chronic alcohol abuse may have an effect on the expression of individual variants, which is masked when using primers that are not selective for individual splice variants. Future studies should investigate the expression 
levels of individual splice variants in the prefrontal cortex of chronic alcoholics.

Neuropathological studies have shown that the damage to the cerebral cortex that occurs as a consequence of chronic alcohol abuse is not uniform. The superior frontal gyrus is particularly susceptible to neuronal loss but other cortical regions, such as the primary motor cortex, do not show neuronal loss (Kril and Harper 1989). Both cortical regions show changes in dendritic arborization, which likely has an effect on synaptic connectivity. Dendritic shrinkage is reversible following prolonged abstinence from alcohol in an experimental model (McMullen et al. 1984).The expression of RGS4 was lower in both the superior frontal gyrus, and the motor cortex, suggesting that the decrease in this transcript is not the result of neuronal loss per se but may instead reflect the changes in dendritic arborization that occurs in both cortical regions. Whether changes in RGS4 expression occur as a direct consequence of chronic alcohol abuse, or as a result of changes in synaptic number, and whether these changes in expression are reversible upon abstinence from alcohol, remain to be elucidated.

In this study, we used a case-control association approach to explore differences in genotypic composition of four RGS4 SNPs, and detected a significantly lower T-C-G (SNP1-4-18) haplotype frequency in alcoholics than in controls. This suggests that this haplotype, although it is not common, may have a protective effect against alcoholism. The significant difference detected in four-marker haplotype analysis may not offer compelling support for SNP7 involvement because its genotypic distribution in controls deviated significantly from HWE, either due to small sample size or population stratification. Confirmation of the current findings, either in a larger case-control population or a family-based approach, is required.

To date, there have been no published studies on the effects of alcohol on the expression of RGS transcripts or proteins in laboratory animals. However, RGS expression is altered by the administration of other drugs of abuse and in other diseases. A microarray study using brain tissue from human schizophrenics showed a decrease in RGS4 mRNA in the prefrontal cortex (Mirnics et al. 2001). One suggested hypothesis was that this decrease could be an adaptive response to 
compensate for a reduction in synapse number or function. This may be true for many neurodegenerative disorders, including alcoholism.

Drug abuse results in neuroadaptive changes in the brain that include the development of tolerance, dependence and withdrawal. RGS4 modulates neurotransmission by impeding G-protein coupled receptor signalling. It is known to modulate a variety of signalling systems, including opioid, serotonergic and dopaminergic receptor systems. This therefore makes it excellent candidate for involvement in mediating the effects of pleiotropic drugs such as alcohol. RGS4 is a negative regulator of MOR (Georgoussi et al. 2006) and studies using knockout mice showed that a loss of RGS4 led to a more-severe physical dependence and withdrawal on morphine due to sensitization of the cAMP pathway in locus ceruleus neurons (Zachariou et al. 2006; Hooks et al. 2008). Since MOR-mediated transmission participates in alcohol reward, tolerance and withdrawal (Sander et al. 1998), RGS4 may play a significant role in the regulation of these events. RGS4 also negatively modulates $5-\mathrm{HT}_{1 \mathrm{~A}}$ regulation of NMDA receptors in the prefrontal cortex (Gu et al.). A loss of RGS4 in the prefrontal cortex of alcoholics may therefore alter glutamate receptor signalling and predispose these neurons to glutamate-mediated excitotoxicity.

In conclusion, we report a difference in expression of RGS4 in the brains of male cirrhotic alcoholics compared with male controls, with no difference in expression in female subjects. We also report that the four RGS4 SNPs (SNP1, 4, 7 and 18) may be associated with alcoholism in European Caucasians at the haplotype level. The haplotype T-C-G (SNP1-4-18) may exert a protective effect against alcoholism. The present findings need to be validated with larger sample size or in familybased association studies.

\section{Experimental Procedures}

\section{Subject Characteristics}

Tissues were collected through The Queensland Brain Bank and The Australian Brain Donor Program NSW Tissue Resource Centre. Ethical clearance for the project was obtained from the 
Griffith University Human Ethics Committee (Protocol Number: MSC/02/06/HREC). The cerebellum and brainstem were detached from the cerebrum by sectioning through the upper midbrain at the level of the superior colliculus. The cerebrum was hemi-sected, with one half being taken for pathological examination. Cortical and sub-cortical pieces were dissected from the other hemisphere, immersed in $10 \mathrm{vol}$ of $0.32 \mathrm{M}$ sucrose, and slowly frozen as previously described for the optimal preservation of synaptosomal function (Dodd et al. 1986). Frozen tissue pieces were stored at $-70^{\circ} \mathrm{C}$ until required.

For genotyping studies, DNA was extracted from 125 controls and 115 alcoholics. Subjects were classified by their daily average ethanol consumption in most of their adult life as reported in their medical records. Controls were those who consumed an average of $<20 \mathrm{~g}$ of ethanol per day or were teetotalers; alcoholics were those who had a mean intake of $>80 \mathrm{~g}$ of ethanol per day (for 30 years on average). All cases were of European origin. No schizophrenic case was included.

Expression studies were performed on a subset of the above cohort. Total RNA was extracted from the superior frontal gyrus (Brodmann areas 6 and 8) and primary motor cortex (area 4) of 24 controls and 40 alcoholics who were matched as closely as possible for PMI and age at death. There was no significant difference between case groups for either age at death $\left(F_{2,61}=2.64, P=0.08\right)$ or PMI $\left(F_{2,61}=0.4, P=0.7\right)$. Fresh brain weights were measured at autopsy for each case. There was no significant difference in brain weight between groups $\left(F_{2,61}=2.57, P=0.08\right)$. For expression studies, alcoholics were further divided into those with (27 cases) or without (13 cases) pathologically confirmed cirrhosis of the liver. Exact alcohol consumption details were not available in every case, but in a related study drawing on the same bank of tissue, the average daily consumption rate in alcoholics without alcohol-associated disease was 13 standard drinks (130 g ethanol), while for alcoholics with cirrhosis, it was 25 standard drinks (250 g ethanol) (Dodd et al. 2004). Cases with a history of poly-drug abuse or other neurological conditions were excluded. Brief details of the cases are shown in Table 3. 


\section{Total RNA Extraction}

Total RNA was extracted from the superior frontal gyrus and primary motor cortex using Trizol ${ }^{\mathrm{TM}}$ (Gibco BRL, Invitrogen, Mt Waverley, Vic, Australia) according to the manufacturer's instructions. In brief, $5 \mathrm{~mL}$ Trizol $^{\mathrm{TM}}$ was added to a $0.5 \mathrm{~g}$ piece of frozen brain tissue, homogenized on ice with a polytron (Kinematika, Switzerland) for $30 \mathrm{~s}$ and incubated for $5 \mathrm{~min}$ at room temperature.

Chloroform (1 mL) was added and the tube shaken vigorously for $15 \mathrm{~s}$, incubated for $2 \mathrm{~min}$ and centrifuged at $10000 \mathrm{xg}$ for $20 \mathrm{~min}$ at $4^{\circ} \mathrm{C}$. Isopropanol $(2.5 \mathrm{~mL})$ was added to the aqueous phase and the sample was incubated at room temperature for 10 min prior to centrifugation at $10000 \times \mathrm{g}$ for $15 \mathrm{~min}$ at $4^{\circ} \mathrm{C}$. The supernatant was removed and the pellet resuspended in $1 \mathrm{~mL} 75 \%$ ethanol and centrifuged at $10000 \mathrm{xg}$ for $20 \mathrm{~min}$. The ethanol was removed and the pellet was air-dried. DEPC-treated water $(\sim 50 \mu \mathrm{L})$ was added to the RNA pellet and incubated for 10 min at $60^{\circ} \mathrm{C}$. RNA quantity was measured by absorbance at $260 \mathrm{~nm}$. The RNA was then dispensed in $20 \mu \mathrm{L}$ aliquots and stored at $-70^{\circ} \mathrm{C}$ until required. RNA quality was assessed by agarose gel electrophoresis and an Agilent 2100 Bioanalyzer (Agilent, Palo Alto, CA, USA) and showed minimal degradation.

\section{Reverse Transcription}

Samples were reverse-transcribed using an Oligo $(\mathrm{dT})_{20}$ mer. A mix of $3.8 \mu \mathrm{M}$ oligo $(\mathrm{dT})_{20}$ (SigmaAldrich, Castle Hill, NSW, Australia), $2 \mu$ g total RNA, 0.77 mM dNTPs (Promega, Annandale, NSW, Australia) in a final volume of $13 \mu \mathrm{L}$ with DEPC-treated water, was incubated at $65^{\circ} \mathrm{C}$ for 5 min and placed on ice for at least $1 \mathrm{~min} .4 \mu \mathrm{L} 5 \mathrm{x}$ first-strand synthesis buffer, $50 \mathrm{mM}$ dithiothreitol (DTT), $40 \mathrm{U}^{\mathrm{RNaseOUT}}{ }^{\mathrm{TM}}$ and $200 \mathrm{U}$ Superscript ${ }^{\mathrm{TM}}$ III (Invitrogen) were added and the solution incubated at $50^{\circ} \mathrm{C}$ for $1 \mathrm{~h}$. The reaction was deactivated by heating to $70^{\circ} \mathrm{C}$ for $15 \mathrm{~min}$. Samples were aliquoted and stored at $-70^{\circ} \mathrm{C}$ until required.

\section{Primer Design}


Primers were designed using Primer Express ${ }^{\circledR}$ v1.5 Software (Applied Biosystems, Scoresby, Vic, Australia) and synthesised by Sigma-Aldrich. Each primer set was verified for gene specificity using BLAST from the GenBank non-redundant nucleotide sequence database. All of the assays were designed such that at least one of the primer pair spanned an exon boundary to eliminate gDNA amplification. The primers for RGS4 amplify three of the five known splice variants; RGS4-1 (NM_001102445.2), RGS4-2 (NM_005613.5) and RGS4-3 (NM_001113380.1). The sequence of the primers is shown in Table 4.

Table 4 about here

\section{Real Time PCR}

Real Time PCR was carried out using an ABI 7000 sequencer (Applied Biosystems) with SYBR ${ }^{\circledR}$ Green as the detection system. Primer concentrations were optimized to determine the minimum primer concentration that gave a low threshold cycle and a maximum $\Delta \mathrm{R}_{\mathrm{n}}$ while minimizing nonspecific amplification. Each polymerase chain reaction (PCR) on the 96-well plate consisted of 5 ng of cDNA, $12.5 \mu \mathrm{L}$ SYBR ${ }^{\circledR}$ Green PCR Master Mix (Applied Biosystems), $300 \mathrm{nM}$ of each pair of oligonucleotide primers in a $25 \mu \mathrm{L}$ final volume per well. Wells with no template were included for each primer set as negative controls. GAPDH was used as the internal reference for determining $\Delta \mathrm{C}_{\mathrm{T}}$ values. All samples were amplified in duplicate.

The amplification plot of fluorescence vs. cycle number was used to set the threshold (T) in the exponential phase of the reaction above the baseline. This was kept constant between runs to allow for analysis between plates. The cycle threshold $\left(\mathrm{C}_{\mathrm{T}}\right)$ was calculated as the cycle number of an amplifying PCR product where it crosses the fixed threshold line. Intra- and inter-assay variability was tested using cDNA serial dilutions generated from universal human reference RNA (Stratagene, Integrated Sciences, Willoughby, NSW, Australia) on three separate days for each primer pair.

The difference in the mean $\mathrm{C}_{\mathrm{T}}$ values of the duplicate samples against the housekeeping genes were 
calculated using Microsoft Excel to give the $\Delta \mathrm{C}_{\mathrm{T}}$. The relative quantitation value was then expressed as $2^{-\Delta \mathrm{C}_{\mathrm{T}}}$ for presentation as outlined in User Bulletin \#2: ABI Prism 7700 Sequence Detection System using the comparative $\mathrm{C}_{\mathrm{T}}$ method (Applied Biosystems).

\section{DNA Extraction and Genotyping}

Genomic DNA was extracted from human brain tissue by phenol/chloroform method followed by ethanol precipitation.

SNP1, 4 and 18 were genotyped by PCR-RFLP method. In brief, 10 ng of sample DNA was added into the reaction mix, which consisted of 1x PCR buffer with $\mathrm{MgCl}_{2}, 200 \mu \mathrm{M}$ dNTPs, forward and reverse primers at $800 \mathrm{nM}$ each and 0.3 U Taq DNA polymerase. Amplification cycle included a 3minute $95^{\circ} \mathrm{C}$ initial denaturation step, followed by 35 cycles of $95^{\circ} \mathrm{C}$ for $30 \mathrm{~s}$, annealing for $30 \mathrm{~s}$ and $72^{\circ} \mathrm{C}$ for $30 \mathrm{~s}$, and lastly at $72^{\circ} \mathrm{C}$ for 7 mins for elongation. The PCR products were then incubated with restriction enzyme overnight. Final products were loaded onto an agarose gel (2-4\%) for the determination of enzyme digestion pattern. Details of the protocols are listed in Table 5.

\section{Table 5 about here}

High resolution melting (HRM) was used for SNP7 genotyping as the PCR-RFLP protocol yielded ambiguous digestion patterns. HRM determines genotypes by measuring the change in fluorescence of the sample with increasing temperature in real time; the melt profiles are distinct for each genotype. 10 ng of sample DNA was added into a reaction mix, which was composed of 1x PCR buffer (without $\mathrm{MgCl}_{2}$ ), $1.5 \mathrm{mM} \mathrm{MgCl} 2,200 \mu \mathrm{M}$ dNTPs, forward and reverse primers (Table 4) at $300 \mathrm{nM}$ each, $1.5 \mu \mathrm{M}$ SYTO9 (Invitrogen, USA) and 1.25 U Taq Gold DNA polymerase (Applied Biosystem, USA). This $25 \mu \mathrm{L}$ reaction mixture then underwent PCR followed by HRM in RotorGene 6000TM Real-time Rotary Analyzer (Corbett Life Science, Australia). The amplification procedure consisted of $95^{\circ} \mathrm{C}$ for 2 mins, 45 cycles of $95^{\circ} \mathrm{C}$ for $5 \mathrm{~s}$ and $58^{\circ} \mathrm{C}$ for $10 \mathrm{~s}$, and $72^{\circ} \mathrm{C}$ for 2 mins. A 2-minute pre-hold applied before the HRM procedure (temperature increased from $73^{\circ} \mathrm{C}$ to 
$83^{\circ} \mathrm{C}$ at a rate of $0.1^{\circ} \mathrm{C}$ per 2 seconds). Rotor-Gene 6000 Series Software v1.7 (Corbett LifeScience, Australia) was used to analyse the resultant curves. Genotyping amplimers of all SNPs were validated by sequencing.

\section{Analysis of data}

Analysis of the expression data was performed using STATISTICA 7.0 (Statsoft Pacific Pty Ltd, Melbourne, Australia). Analysis of Variance (ANOVA) was followed by the relevant post hoc test where appropriate. The effects of age at death, PMI, brain weight and gender were determined. Differences between the slopes of the regression lines were also tested. When regression was significant, covariance analysis was used to normalize the data and to produce adjusted least-square means and S.E.M. values.

HWE of genotype frequencies of each SNP was tested by exact tests using the DeFinetti programme (http://ihg2.helmholtz-muenchen.de/ihg/snps.html). Genotype and allele frequencies were compared between cases and controls by $\chi^{2}$ test using SPSS 16 (SPSS, USA). HaploView v4.1 (Barrett et al. 2005) was used for linkage disequilibrium (LD) calculation ( $D^{\prime}$ and $r^{2}$ ), haplotype prediction and case-control haplotype frequency comparison ( $\chi^{2}$ test with 10000 permutations to correct for multiple testing bias).

Acknowledgments: We would like to acknowledge the Queensland Brain Bank, School of Chemistry and Molecular Biosciences, the University of Queensland in collaboration with the Australian Brain Bank Network and the Australian Brain Donor Programs NSW Tissue Resource Centre who provided the alcoholic and control brain tissue for analysis. Allison Eckert and Donna Sheedy provided detailed information on each of the cases used. We thank the next of kin for providing informed written consent for the studies. Financial support was provided by the National Institute of Alcoholism and Alcohol Abuse (USA, NIH AA12404) (R01 AA012725-04) and the NHMRC. Ada M.-C. Ho was funded by the Margaret Mittelheuser Commemorative Fellowship from AFUW-Q/FFI during the course of this study. 


\section{References}

Barrett J. C., Fry B., Maller J. and Daly M. J. (2005) Haploview: analysis and visualization of LD and haplotype maps. Bioinformatics 21, 263-265.

Bishop G. B., Cullinan W. E., Curran E. and Gutstein H. B. (2002) Abused drugs modulate RGS4 mRNA levels in rat brain: comparison between acute drug treatment and a drug challenge after chronic treatment. Neurobiol Dis 10, 334-343.

Buckholtz J. W., Meyer-Lindenberg A., Honea R. A., Straub R. E., Pezawas L., Egan M. F., Vakkalanka R., Kolachana B., Verchinski B. A., Sust S., Mattay V. S., Weinberger D. R. and Callicott J. H. (2007) Allelic variation in RGS4 impacts functional and structural connectivity in the human brain. J Neurosci 27, 1584-1593.

Chowdari K. V., Bamne M., Wood J., Talkowski M. E., Mirnics K., Levitt P., Lewis D. A. and Nimgaonkar V. L. (2008) Linkage disequilibrium patterns and functional analysis of RGS4 polymorphisms in relation to schizophrenia. Schizophr Bull 34, 118-126.

Chowdari K. V., Mirnics K., Semwal P., Wood J., Lawrence E., Bhatia T., Deshpande S. N., B K. T., Ferrell R. E., Middleton F. A., Devlin B., Levitt P., Lewis D. A. and Nimgaonkar V. L. (2002) Association and linkage analyses of RGS4 polymorphisms in schizophrenia. Hum Mol Genet 11, 1373-1380.

de la Monte S. M. (1988) Disproportionate atrophy of cerebral white matter in chronic alcoholics. Arch Neurol 45, 990-992.

Ding L. and Hegde A. N. (2009) Expression of RGS4 splice variants in dorsolateral prefrontal cortex of schizophrenic and bipolar disorder patients. Biol Psychiatry 65, 541-545.

Ding L., Mychaleckyj J. C. and Hegde A. N. (2007) Full length cloning and expression analysis of splice variants of regulator of G-protein signaling RGS4 in human and murine brain. Gene 401, 4660 .

Dodd P. R., Foley P. F., Buckley S. T., Eckert A. L. and Innes D. J. (2004) Genes and gene expression in the brain of the alcoholic. Addict Behav 29, 1295-1309.

Dodd P. R., Hardy J. A., Baig E. B., Kidd A. M., Bird E. D., Watson W. E. and Johnston G. A. (1986) Optimization of freezing, storage, and thawing conditions for the preparation of metabolically active synaptosomes from frozen rat and human brain. Neurochem Pathol 4, 177-198.

Georgoussi Z., Leontiadis L., Mazarakou G., Merkouris M., Hyde K. and Hamm H. (2006) Selective interactions between G protein subunits and RGS4 with the C-terminal domains of the mu- and delta-opioid receptors regulate opioid receptor signaling. Cell Signal 18, 771-782.

Gu Z., Jiang Q. and Yan Z. (2007) RGS4 modulates serotonin signaling in prefrontal cortex and links to serotonin dysfunction in a rat model of schizophrenia. Mol Pharmacol 71, 1030-1039.

Harding A. J., Halliday G. M., Ng J. L., Harper C. G. and Kril J. J. (1996) Loss of vasopressin- 
immunoreactive neurons in alcoholics is dose-related and time-dependent. Neuroscience 72, 699708.

Harper C. (1998) The neuropathology of alcohol-specific brain damage, or does alcohol damage the brain? J Neuropathol Exp Neurol 57, 101-110.

Harper C. G., Kril J. J. and Holloway R. L. (1985) Brain shrinkage in chronic alcoholics: a pathological study. Br Med J (Clin Res Ed) 290, 501-504.

Harper C. G., Smith N. A. and Kril J. J. (1990) The effects of alcohol on the female brain: a neuropathological study. Alcohol Alcohol 25, 445-448.

Hooks S. B., Martemyanov K. and Zachariou V. (2008) A role of RGS proteins in drug addiction. Biochem Pharmacol 75, 76-84.

Jacobson R. (1986) The contributions of sex and drinking history to the CT brain scan changes in alcoholics. Psychol Med 16, 547-559.

Kril J. J. and Harper C. G. (1989) Neuronal counts from four cortical regions of alcoholic brains. Acta Neuropathol (Berl) 79, 200-204.

Kril J. J. and Halliday G. M. (1999) Brain shrinkage in alcoholics: a decade on and what have we learned? Prog Neurobiol 58, 381-387.

Kril J. J., Halliday G. M., Svoboda M. D. and Cartwright H. (1997) The cerebral cortex is damaged in chronic alcoholics. Neuroscience 79, 983-998.

Lewohl J. M., Wang L., Miles M. F., Zhang L., Dodd P. R. and Harris R. A. (2000) Gene expression in human alcoholism: microarray analysis of frontal cortex. Alcohol Clin Exp Res 24, 1873-1882.

Lewohl J. M., Van Dyk D. D., Craft G. E., Innes D. J., Mayfield R. D., Cobon G., Harris R. A. and Dodd P. R. (2004) The application of proteomics to the human alcoholic brain. Ann N Y Acad Sci 1025, $14-26$.

Liu J., Lewohl J. M., Dodd P. R., Randall P. K., Harris R. A. and Mayfield R. D. (2004) Gene expression profiling of individual cases reveals consistent transcriptional changes in alcoholic human brain. J Neurochem 90, 1050-1058.

Mann K., Batra A., Gunthner A. and Schroth G. (1992) Do women develop alcoholic brain damage more readily than men? Alcohol Clin Exp Res 16, 1052-1056.

Mayfield R. D., Lewohl J. M., Dodd P. R., Herlihy A., Liu J. and Harris R. A. (2002) Patterns of gene expression are altered in the frontal and motor cortices of human alcoholics. J Neurochem 81, 802-813.

McMullen P. A., Saint-Cyr J. A. and Carlen P. L. (1984) Morphological alterations in rat CA1 hippocampal pyramidal cell dendrites resulting from chronic ethanol consumption and withdrawal. $J$ Comp Neurol 225, 111-118.

Mirnics K., Middleton F. A., Stanwood G. D., Lewis D. A. and Levitt P. (2001) Disease-specific 
changes in regulator of G-protein signaling 4 (RGS4) expression in schizophrenia. Mol Psychiatry 6, 293-301.

Namkung J., Kim Y. and Park T. (2005) Whole-genome association studies of alcoholism with loci linked to schizophrenia susceptibility. BMC Genet 6 Suppl 1, S9.

Nestler E. J. and Aghajanian G. K. (1997) Molecular and cellular basis of addiction. Science 278, 58-63.

Pfefferbaum A., Rosenbloom M., Deshmukh A. and Sullivan E. (2001) Sex differences in the effects of alcohol on brain structure. Am J Psychiatry 158, 188-197.

Sander T., Gscheidel N., Wendel B., Samochowiec J., Smolka M., Rommelspacher H., Schmidt L. G. and Hoehe M. R. (1998) Human mu-opioid receptor variation and alcohol dependence. Alcohol Clin Exp Res 22, 2108-2110.

Schweinsburg B. C., Alhassoon O. M., Taylor M. J., Gonzalez R., Videen J. S., Brown G. G., Patterson T. L. and Grant I. (2003) Effects of alcoholism and gender on brain metabolism. Am J Psychiatry 160, 1180-1183.

Siderovski D. P. and Willard F. S. (2005) The GAPs, GEFs, and GDIs of heterotrimeric G-protein alpha subunits. Int J Biol Sci 1, 51-66.

Tesmer V. M., Kawano T., Shankaranarayanan A., Kozasa T. and Tesmer J. J. (2005) Snapshot of activated G proteins at the membrane: the Galphaq-GRK2-Gbetagamma complex. Science 310, 1686-1690.

Wang G. J., Volkow N. D., Fowler J. S., Franceschi D., Wong C. T., Pappas N. R., Netusil N., Zhu W., Felder C. and Ma Y. (2003) Alcohol intoxication induces greater reductions in brain metabolism in male than in female subjects. Alcohol Clin Exp Res 27, 909-917.

Wilkinson. L., Hill. M. and Vang. E. (1992) SYSTAT: Statistics, Version 5.2 Edition. SYSTAT, Inc, Evanston, IL.

Willars G. B. (2006) Mammalian RGS proteins: multifunctional regulators of cellular signalling. Semin Cell Dev Biol 17, 363-376.

Zachariou V., Renthal W., Gold S. J., Young K. H., Su J., Rahman Z., Howland D., Ring R., Han M. and Nestler E. J. (2006) RGS4 modulates morphine reward and depndence, in Society for Neuroscience Abstract, p 742.

Zachariou V., Georgescu D., Sanchez N., Rahman Z., DiLeone R., Berton O., Neve R. L., SimSelley L. J., Selley D. E., Gold S. J. and Nestler E. J. (2003) Essential role for RGS9 in opiate action. Proc Natl Acad Sci U S A 100, 13656-13661.

Zhang F., St Clair D., Liu X., Sun X., Sham P. C., Crombie C., Ma X., Wang Q., Meng H., Deng W., Yates P., Hu X., Walker N., Murray R. M., Collier D. A. and Li T. (2005) Association analysis of the RGS4 gene in Han Chinese and Scottish populations with schizophrenia. Genes Brain Behav 4, 444-448. 


\section{Figure Legends}

Figure 1: RGS4 transcript expression. Expression of RGS4 in the superior frontal gyrus and sensory motor cortex of cirrhotic alcoholics (open bars) is significantly lower than that of controls (black bars; frontal, $P<0.01$; motor, $P=0.01$ ) or non-cirrhotic alcoholics (shaded bars; frontal, $P<0.02$; motor, $P=0.03)$. Mean $\Delta \mathrm{C}_{\mathrm{T}}$ values were converted to $2^{-\Delta \mathrm{C}_{\mathrm{T}}}$ values for presentation. The data presented in the graph includes cases and controls of both sexes. Error bars represent S.E.M.

Figure 2: RGS7 transcript expression. Expression of RGS7 in the superior frontal gyrus and sensory motor cortex of controls (black bars), non-cirrhotic alcoholics (shaded bars) and cirrhotic alcoholics (open bars). There was no significant difference in expression between groups. Mean $\Delta \mathrm{C}_{\mathrm{T}}$ values

were converted to $2^{-\Delta \mathrm{C}_{\mathrm{T}}}$ values for presentation. The data presented in the graph includes cases and controls of both sexes. Error bars represent S.E.M. 


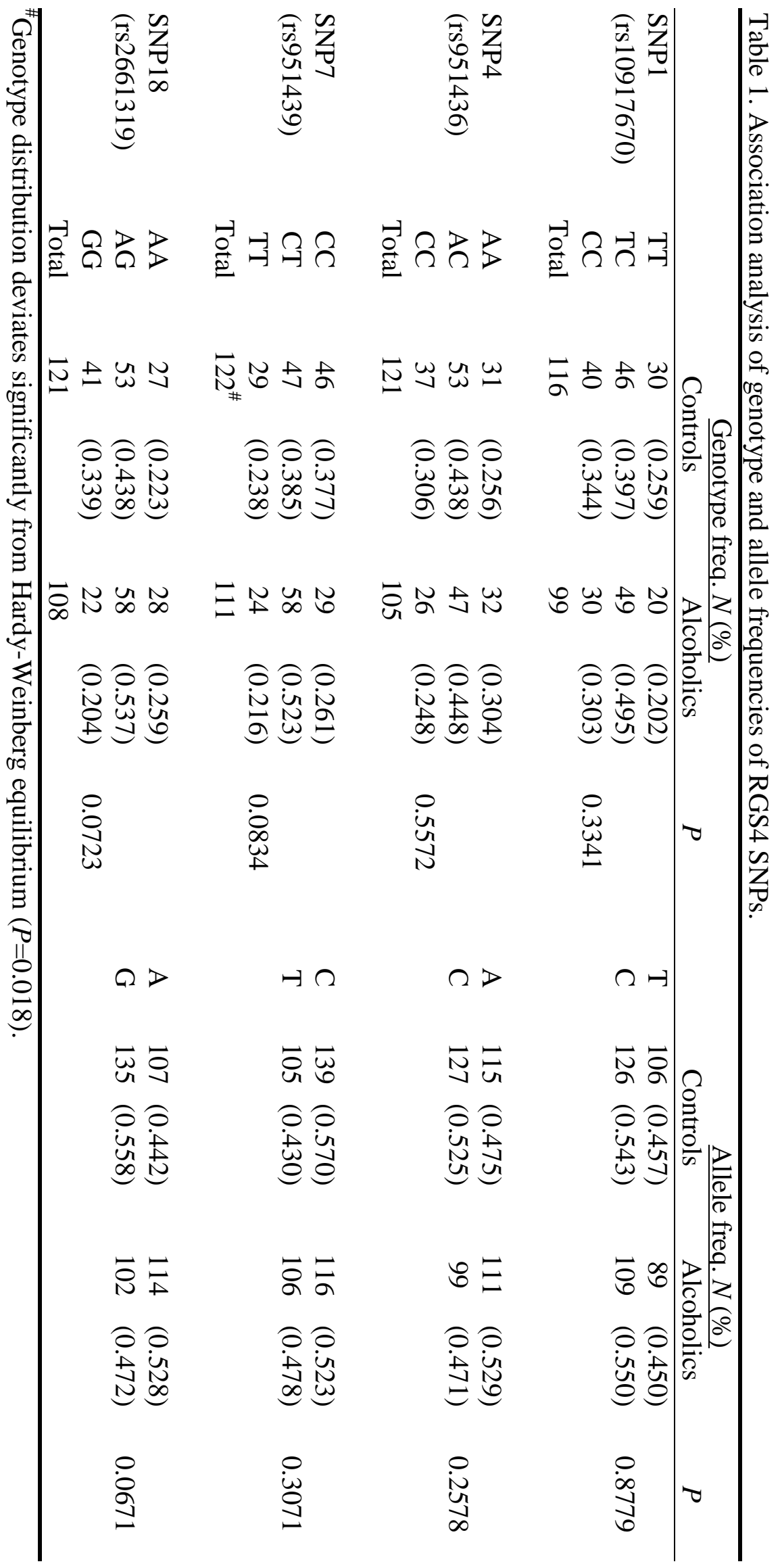




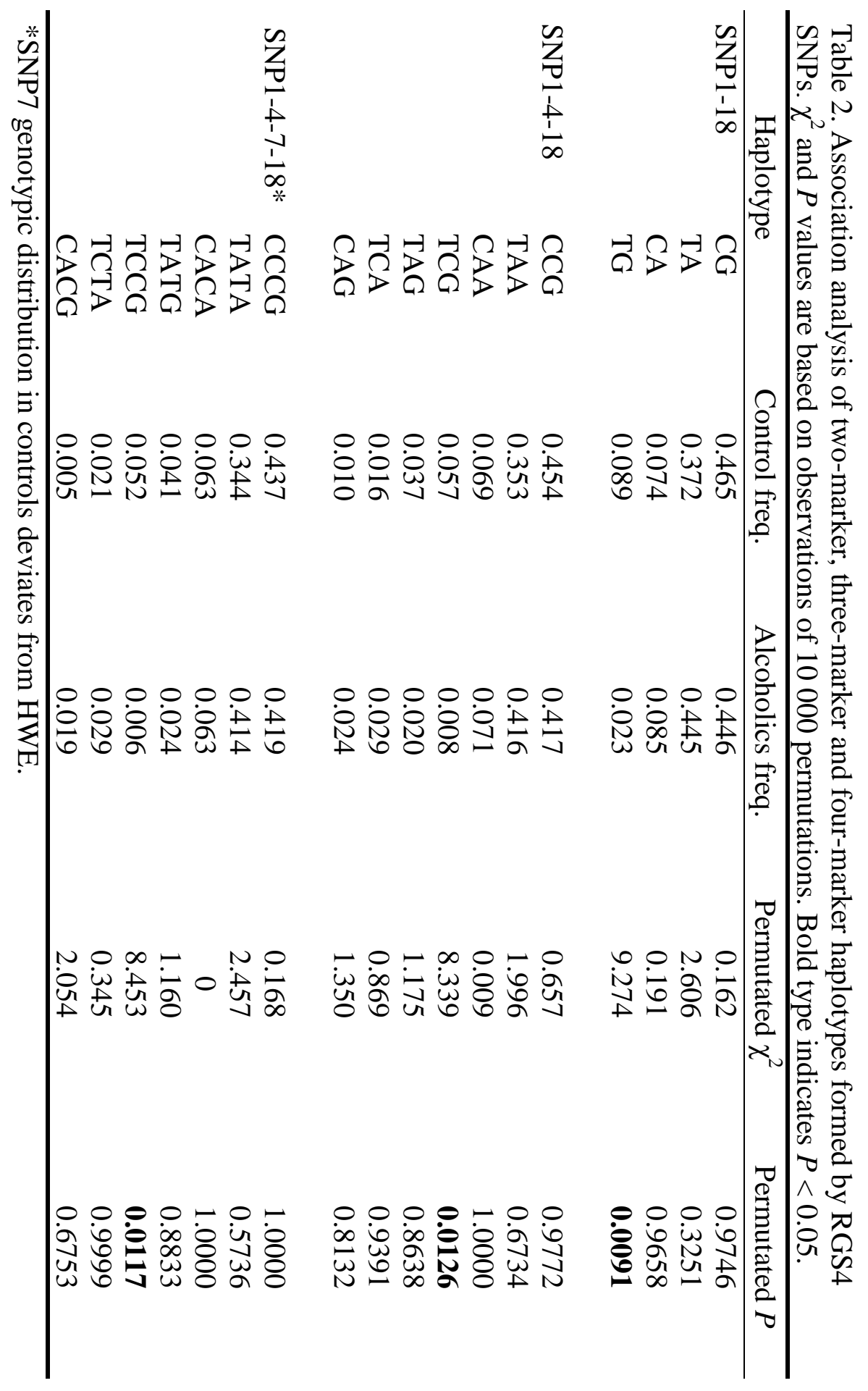




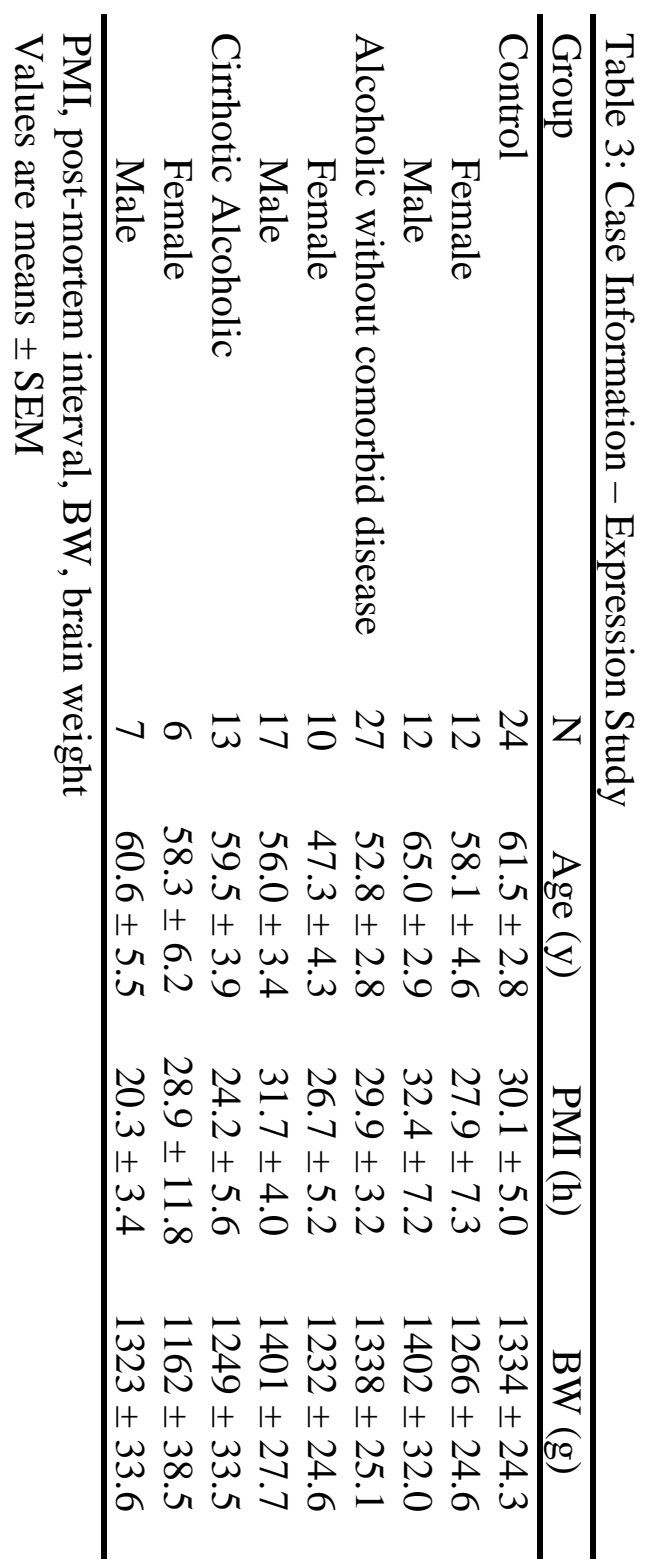




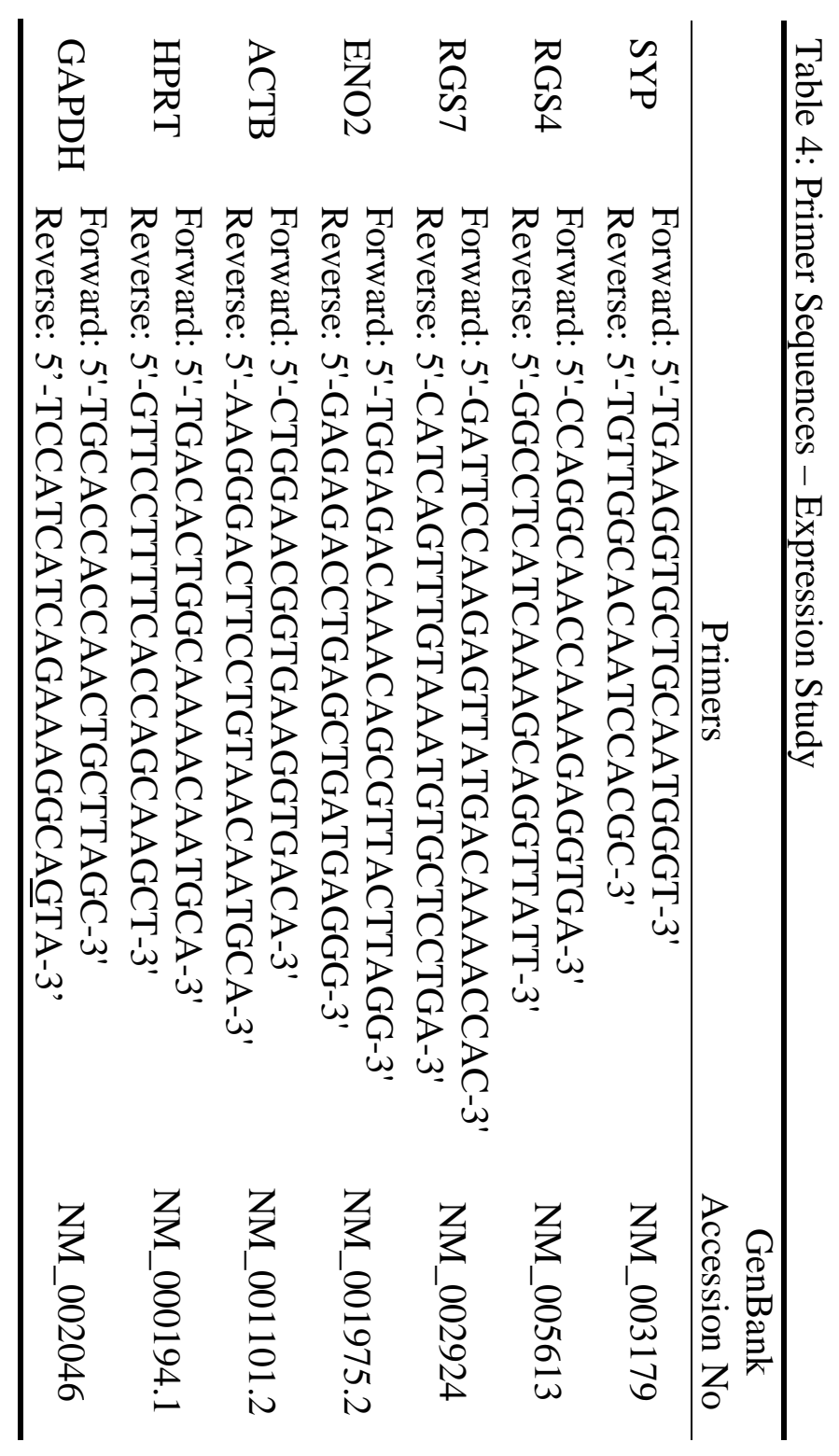




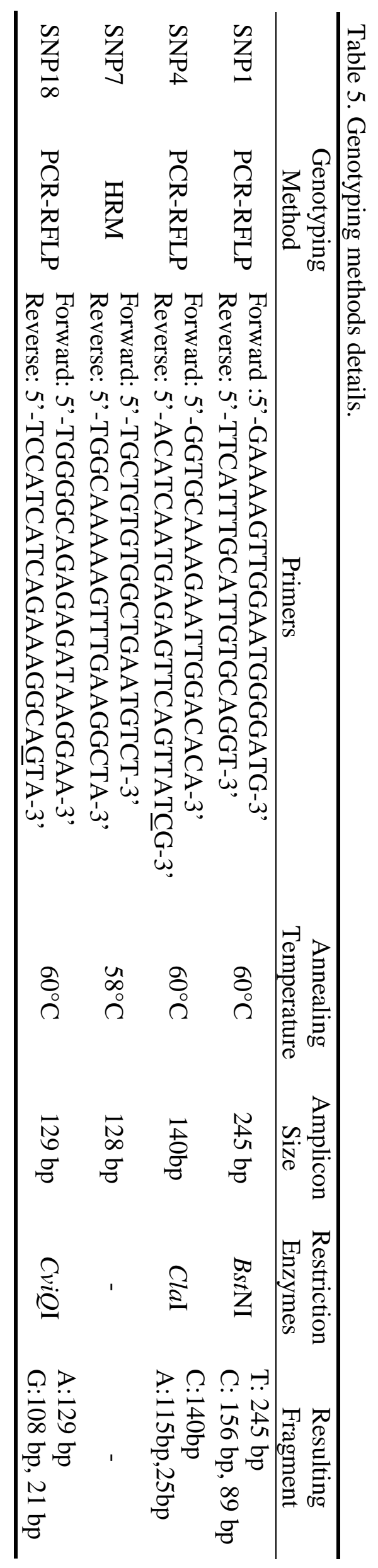

